\section{Highlighting Prosocial Affordances of Science in Textbooks to Promote Science Interest}

\author{
Jeanette Zambrano ${ }^{* *}$, Garam Ann Lee ${ }^{\ddagger}$, Christina C. Leal\$, and Dustin B. Thoman" \\ ${ }^{\dagger}$ Rossier School of Education, University of Southern California, Los Angeles, CA 90089-4035; \\ ${ }^{\ddagger}$ College of Education, Michigan State University, East Lansing, MI 48824; \$Warner School \\ of Education, University of Rochester, Rochester, NY 14627; 'Department of Psychology, \\ San Diego State University, San Diego, CA 92182
}

\begin{abstract}
The prevalent stereotype that scientific fields do not afford opportunities to fulfill goals of helping others deters student interest and participation in science. We investigated whether introductory college science textbooks that highlight the prosocial utility value of science can be used to change beliefs about the affordances of scientific work. In study 1 , undergraduate students who were randomly assigned to read a science textbook chapter with added prosocial utility value expressed greater beliefs that the science topic afforded prosocial goals and increased interest in the scientific topic, compared with two control conditions. Mediation analysis demonstrated that interest was enhanced through increased beliefs that the topic afforded prosocial opportunities. Multiple group comparison tests indicated that underrepresented minority students (i.e., African Americans, Latinos, and Native Americans) might benefit the most from efforts to strengthen prosocial affordance beliefs. In study 2 , we conducted a brief landscape analysis of science textbooks and found that texts are missing opportunities to emphasize the prosocial utility value of science. We discuss recommendations for science educators, curriculum designers, and researchers who want to increase and broaden science participation.
\end{abstract}

\section{INTRODUCTION}

Researchers, educators, and policy makers share the goal of increasing interest and participation in the sciences to address concerns about maintaining the United States' competitiveness in the global economy and ensuring access to science careers for all students (National Science Foundation [NSF], 2019; National Science Board, 2020). National reports recommend focusing on undergraduate retention as the most efficient and cost-effective strategy to increase and diversify the science, technology, engineering, and mathematics (STEM) workforce (President's Council of Advisors on Science and Technology, 2012). Because much of the attrition among undergraduate science students occurs in the earliest stages of their college experiences (Almatrafi et al., 2017), efforts to retain students at this academic career stage are most likely to plug the largest leaks in the STEM pipeline. A key research strategy identified for addressing barriers to student retention involves integrating principles from cognitive and learning sciences with discipline-based research to improve undergraduate classroom experiences and learning outcomes (Davidesco and Milne, 2019).

Although student competence (or doing well) in science is a necessary component for retention, it is not sufficient and does not offer a full picture as to why students choose to persist in or leave science majors (e.g., Seymour and Hewitt, 1997; Renninger et al., 2015; Thoman et al., 2019). Value (i.e., whether science is useful or important) and interest also matter for educational and career choices, above and beyond competence in science (e.g., Wigfield and Eccles, 2000; Valla and Ceci, 2014; Harackiewicz et al., 2016; Steinberg and Diekman, 2018). When students perceive
Sarah L. Eddy, Monitoring Editor Submitted Sep 12, 2019; Revised Apr 6, 2020; Accepted Apr 17, 2020

CBE Life Sci Educ September 1, 2020 19:ar24

DOI:10.1187/cbe.19-09-0176

*Address correspondence to: Jeanette Zambrano (zambranj@usc.edu).

(C) 2020 J. Zambrano et al. CBE-Life Sciences Education ( 2020 The American Society for Cell Biology. This article is distributed by The American Society for Cell Biology under license from the author(s). It is available to the public under an Attribution-Noncommercial-Share Alike 3.0 Unported Creative Commons License (http://creativecommons.org/licenses/ by-nc-sa/3.0)

"ASCB®" and "The American Society for Cell Biology $\circledR^{\prime \prime}$ are registered trademarks of The American Society for Cell Biology. 
science as useful, they are more likely to be interested in science (e.g., Hulleman and Harackiewicz, 2009). Unfortunately, the applicability and relevance of science to people's lives are seldom emphasized in foundational undergraduate science classes. In this study, we draw from the communal goal affordance perspective- the idea that science fields are perceived as lacking opportunities to fulfill communal goals, which makes them less attractive, less valuable, and less aligned with people's goals of working with and helping others (Diekman et al., 2010) - to address declines in science interest. In particular, we target science textbooks used in foundational science courses to change beliefs that science does offer opportunities to help others. In the following sections, we review research on communal goal affordance beliefs and how these beliefs shape science interest. Then we describe our strategy to focus on one aspect of communal affordances (i.e., prosocial affordances) and convey our rationale for using textbooks as tools to change beliefs about the nature and value of scientific work.

\section{STEREOTYPES ABOUT SCIENCE}

In the United States, stereotypes about science include robust beliefs that science fields do not afford opportunities to fulfill communal goals (Cheryan et al., 2015). Communion involves a drive toward people in terms of working with, helping, and developing relationships with others; and its counterpart, agency, involves a drive for one's self in terms of one's own achievement, status, and independence (Pöhlmann, 2001; Abele and Wojciszke, 2007). Communal and agentic goals are critical for understanding science participation, because science fields are perceived as unbalanced in their ability to afford both communal and agentic opportunities. That is, the culture of science is stereotyped as highly agentic, whereas opportunities to fulfill communal goals are perceived as missing from science majors and careers (Diekman et al., 2017). This perceived lack of opportunity to fulfill communal goals in science can subsequently deter students from engaging, or continuing to engage, in scientific work (for a review, see Boucher et al., 2017).

The communal goal affordance framework has been used to explain gender and racial/ethnic group differences in science representation and career interest (e.g., Diekman et al., 2010; Brinkman and Diekman, 2016). Although engaging in communal work is a particularly strong goal orientation among women (e.g., Morgan et al., 2001) and underrepresented minorities (URMs; i.e., African Americans, Latinos, and Native Americans; e.g., Tyler et al., 2006; Fryberg and Markus, 2007; Gibbs and Griffin, 2013; Smith et al., 2014; Thoman et al., 2015; Jackson et al., 2016), the communal goal congruity logic has also been applied more broadly. These studies have demonstrated positive main effects of communal goals on outcomes such as science topic interest and science career interest (e.g., Brown et al., 2015b, 2018; LaMeres et al., 2019). Therefore, stereotypes about the independent, individual achievement-oriented, socially isolated, and esoteric culture of science act as "educational gatekeepers" for women, URMs, and anyone else who seeks to fulfill communal goals (Cheryan et al., 2015, p. 2).

\section{IMPORTANCE OF AFFORDANCE BELIEFS FOR SCIENCE INTEREST}

Undergraduate students who believe that science fields do not afford opportunities to fulfill communal goals experience less science interest. Correlational and longitudinal evidence demonstrates that students who identify greater communal affordances in science on their own express greater science career interest, research task positivity, intrinsic science motivation, and interest in science classes than students who see science fields and topics as less communal (e.g., Weisgram and Bigler, 2006; Diekman et al., 2010; Klotz et al., 2014; Brown et al., 2015a; Fuesting et al., 2017; LaMeres et al., 2019). Experimental evidence demonstrates that increasing beliefs that science affords communal opportunities can boost science career interest and positivity toward science (e.g., Diekman et al., 2011; Brown et al., 2015a; Clark et al., 2016). For example, Brown and colleagues (2015a) examined the effect of communal affordance beliefs on biomedical science students' interest by randomly assigning students to read different versions of brief research descriptions. They found that emphasizing the communal utility value (i.e., how science can be used to fulfill communal goals) in those research descriptions increased student interest in that research and in working in a research lab. They found that their communal utility value intervention indirectly impacted students' interest, because students believed that biomedical research was communal, and thus more important. Changing students' beliefs about the value of scientific work, therefore, offers a pathway for supporting student interest in science (Steinberg and Diekman, 2017).

Consistent with the communal goal affordance perspective, group differences in how communal affordance beliefs affect interest have emerged in the literature. These group differences have generally been studied in two ways. Researchers have primarily focused on how people's goal orientations influence the value of communal opportunities in science. This approach suggests that, because URMs and women value communal goals more highly than do whites and men, beliefs about the extent to which communal opportunities are present or absent in their work may have a greater impact on their interest. For example, using longitudinal survey data from biomedical student research assistants, Thoman and colleagues (2015) found that beliefs that science affords opportunities to help others predicted greater science career interest for URM students but not for white students. Other studies, however, have not found group differences: in some studies, communal affordance beliefs were associated with interest for everyone (e.g., Brown et al., 2015a). Thus, there is mixed evidence about the hypothesis that different groups differ in the extent to which they value communal goals.

What has received less attention is the idea that group differences exist in the perception of communal affordances (Clark et al., 2016). This hypothesis suggests that URMs' and/or women's heightened communal goal orientations influence the extent to which communal cues shift their beliefs about science as affording communal opportunities. Consider, for example, a person who views themselves as "hardworking" and highly values this attribute. Decades of research on how beliefs or values are activated and used to respond to a stimulus suggests that, when forming impressions of others, this person is more likely to have hardworking-related information readily accessible in their mind and will more easily and swiftly recognize other people as a member of the hardworking category (Higgins, 1996). Therefore, the more that a given belief or attribute is important to a person, the more likely it is to stand out as prominent in their cognitive field, enter their thoughts more readily, and be remembered over time 
(Higgins et al., 1982). In line with this cognitive interpersonal perceptual bias, because URMs and/or women strongly endorse communal goals, and have them more salient and accessible, they may be more sensitive to cues that signal the presence or absence of communal opportunities when forming their impressions of scientific work. This heightened sensitivity, or cognitive predisposition, to notice and access communal information should produce greater shifts in communal affordance beliefs for these groups of people when presented with communal information about science (e.g., Clark et al., 2016; Moulton-Tetlock et al., 2018). Both possibilities are explored in this study.

\section{EMPHASIZING PROSOCIAL AFFORDANCES IN TEXTBOOKS}

Communal goals involve a drive to work with, help, and develop relationships with others. To focus on which aspects of communal goals might be most impactful for interest, Brown and colleagues (2015a) tested whether different types of communal goals might be more or less important. They found that, compared with students who read descriptions that convey science as affording opportunities to work with and form relationships with others, students who read about science research as being used to help others reported greater interest and positivity toward science. A targeted focus on prosocial utility value, or how science can be used to help others, give back to communities, and tend to the needs of others, may yield the largest impact on science interest. For this reason, this study focused on highlighting the prosocial utility value of science to change science affordance beliefs and science interest.

Shifting the representations of scientific work and values offers a new route to broadening science for URMs, women, and communally oriented people (Boucher et al., 2017). Stereotypes about the socially isolated and esoteric nature of scientific fields undermine interest, even though these beliefs are not consistent with national policy goals, such as advancing "national health, prosperity, and welfare" (National Science Foundation Act, 1950). In reality, scientific work is fundamentally - even if sometimes indirectly_-prosocial. Scientists use knowledge of momentum to improve car safety for families; they use cell biology to advance medicine and promote longer, healthier lives; knowledge of environmental sciences is used for hurricane prediction and deterring human causalities; and civil engineering is used to improve roads and bridges for the integrity and safety of communities. In federal grant proposals, scientists write statements on broader impacts (National Science Foundation) or translational impacts (National Institutes of Health). Yet, students at the foundational levels of undergraduate science education do not always see these prosocial connections to what they are learning. How can such prosocial utility value connections be transmitted to change science affordance beliefs at the early undergraduate level, where most attrition occurs?

Prior work has highlighted the other-oriented nature of science activities using role models (Clark et al., 2016), high school demonstrations (Weisgram and Bigler, 2006), research experiences (Brown et al., 2015a), psychological interventions (e.g., Yeager et al., 2014), and service-learning curricula (Brinkman and Diekman, 2016) to promote interest, achievement, and participation in STEM. In this study, we tested a different and potentially wider-reaching communication channel: textbooks. Teachers use textbooks to structure content and format their instruction in different ways and to varying degrees (e.g., Remillard, 2005). Student use of textbooks also varies by subject, level, activities (e.g., students read more before an exam), and instructor emphasis (or de-emphasis) on reading (e.g., Collard et al., 2002; Clump et al., 2004; French et al., 2015). Despite this variability, the fact remains that textbooks continue to be used in most science courses as reliable and authoritative sources that provide direction for student learning (Knight, 2015).

Introductory science textbooks are appropriate channels for changing science affordance beliefs, because they are widely used and provide clues about what matters in scientific work, including the values, beliefs, norms, and practices within scientific fields (e.g., McBride, 1994; Stray, 1994). Messages communicated through foundational textbooks "provide the uninitiated their initial view of the discipline," both in terms of what is said and not said within the text (Titus, 1993, p. 38). For these reasons, the strategic inclusion of explicit examples of how science can be used to help others in textbooks could integrate people, social context, and relevance into science learning (Chamany et al., 2008); it could allow students to see the ways in which they can fulfill prosocial goals that they may not otherwise see; and, together with other strategies, it might help change the normal cultural view that scientific fields do not afford opportunities to fulfill prosocial goals.

\section{THE PRESENT STUDY}

Previous empirical work has demonstrated the benefits of emphasizing the communal utility value of science and suggests that highlighting how science can be used to help others (i.e., prosocial utility value) might produce the largest impact on student interest (Brown et al., 2015a). However, when Brown and colleagues (2015a) examined the inclusion of communal utility value on short research statements, they focused on narrow research topics (e.g., lysosomal events) and specific affordance questions about that research. From their findings, it was not clear whether this would translate to the wider level of topic focus found in science textbooks to change broader affordance beliefs of scientific work.

In study 1 , we focused on prosocial utility value and experimentally tested whether we could broaden affordance beliefs across a textbook chapter for a more expansive level of interest across a topic. We also tested whether and how the inclusion of prosocial utility value information affects the interest development process differently for women and URM students. In study 2 , we conducted a brief landscape analysis of whether and how textbooks are currently including prosocial utility value information in biology, chemistry, and physics. To the best of our knowledge, no other study to date has examined the prevalence of utility value (prosocial or not) in textbooks. Across two studies, we considered the practical application of prosocial utility value in science textbooks to change beliefs about the affordances of scientific work in order to promote science interest.

\section{STUDY 1: TESTING THE INCLUSION OF PROSOCIAL UTILITY VALUE IN TEXTBOOKS ON INTEREST}

In study 1 , we tested whether incorporating prosocial utility value into a science textbook chapter would increase students' beliefs that the chapter's topic affords prosocial opportunities and students' interest in the topic. We hypothesized that students randomly assigned to read a textbook with prosocial 
information (vs. the control textbooks) would be more likely to report that the science topic affords opportunities to fulfill prosocial goals and that they would report greater subsequent interest in the topic. We also tested for potential group differences between URMs and/or women in how prosocial affordance beliefs affect interest.

\section{Methods}

Participant Recruitment. Participants were recruited from the introductory psychology class participant pool at a university in southern California. As part of their psychology course, students were required to sign-up and participate in faculty research studies (or complete an alternate writing assignment) in exchange for course credit. To sign up and participate in the research studies, students had to first complete a background questionnaire. After taking this background questionnaire, students were cleared to sign up for research studies in the psychology department through an online portal.

Baseline Measures. We petitioned to add several questions to the participant pool background questionnaire to measure students' previously held beliefs about the science topic (i.e., plant diversity) and their interest in the topic. Therefore, these baseline measures were collected as part of a separate survey (the psychology department background questionnaire) before participants could enroll in any research study. We measured students' affordance beliefs and interest before the experiment in order to strengthen the causal nature of the study, so that differences in students' prosocial affordance beliefs and interest after engaging with the prosocial textbook (vs. the general utility and neutral textbooks) are attributed to the prosocial textbook and not previously held affordance beliefs or interests.

Students' baseline prosocial affordance beliefs (i.e., beliefs that the science topic affords opportunities to fulfill prosocial goals) were measured by having them rate four items ("Please indicate how much you disagree or agree: I think I can apply knowledge of plant diversity to helping others; I think knowledge of plant diversity can be used to give back to my community; I think knowledge of plant diversity is useful for helping other people like me; I think knowledge of plant diversity can be used to attend to others' needs") on scales ranging from 1 (strongly disagree) to 7 (strongly agree). Responses were averaged $(\alpha=0.90)$. This scale was modified from a communal value scale that was originally developed by Pöhlmann (2001). Students' baseline topic interest was measured with one item "I think plant diversity is interesting" on a scale ranging from 1 (strongly disagree) to 7 (strongly agree).

Participants. One hundred ninety-five undergraduate students (70.8\% female; $41.0 \%$ white; 33.3\% URM [i.e., 23.6\% Latino, 9.2\% African American, 0.5\% Native American], 25.1\% Asian; median age $=19)$ from a variety of academic majors $(22.1 \%$ kinesiology, $14.9 \%$ biology/biochemistry, 9.7\% psychology) signed up and volunteered to participate in our Student Engagement Study in exchange for course credit. All participants were at least 18 years old. All study procedures were approved by the university's institutional review board (\#2553099).

Experimental Procedure. Students arrived at the lab at their scheduled appointments and were asked to sit at individual stations. They were asked to read a short chapter and were told that they would be taking a quiz on the content covered in the chapter. Students were told about a quiz at the beginning of the experiment in order to have the activity parallel a real class task in which students read for a purpose and become motivated to learn the material and engage with the textbook (for a discussion on psychological realism and external validity of laboratory experiments, see Berkowitz and Donnerstein, 1982).

Students were randomly assigned to read one of three textbook chapters: 1 ) one that included information about how science can be used to help others (prosocial utility value condition), 2) one that included information about how science can be useful for people but not in a helpful or altruistic way (general utility value condition), or 3) one that did not add utility value connections to science (neutral condition). Next, students completed a series of self-report measures, including prosocial affordance beliefs, topic interest, and perceived competence. Afterward, they took a short quiz on the reading material. Demographic information was also collected. Finally, students were debriefed on the purpose of the study.

Textbooks. All students read a short biology textbook chapter. Adapted from Reece et al. (2014, chapter 29), the textbook chapters were created to resemble a standard textbook. The cover page of each textbook was Biology-Concepts and Connections, 12th edition, and the name of the chapter was "Plant Diversity I: How Plants Colonized Land.” The chapter included six pages of reading content. The content detailed the process of how green algae evolved to form the first land plants and included descriptions about the different classes of plants that have existed. The textbooks across all conditions were identical except for the content added as manipulations. There were six manipulations (four located in the sidebar, two located in the text) and they were evenly dispersed throughout the chapter (one manipulation per page).

Students randomly assigned to the prosocial utility value condition read a textbook chapter that included examples or connections about how a topic or concept can be used to help others or help communities. For example, after a description about distinguishing between different groups of plants, one prosocial utility value manipulation was:

Because of their different structures, vascular plants store their own food and water while nonvascular plants do not. This allows vascular plants to survive during changes in the environment, like during a drought. Knowing which types of plants, like certain vascular plants, will survive during a drought can provide a greater supply of food to communities that have food shortages during extreme conditions.

Alternatively, students randomly assigned to the general utility value condition read a textbook chapter that included examples or connections about how a topic or concept can be used by or applied to humans. Importantly, these connections did not convey the potential to help others. For example, after the same description about distinguishing between different groups of plants, the general utility value manipulation was:

Because of their different structures, vascular plants have two different types of vascular tissues, while nonvascular plants do 
not. The fibers found inside the vascular tissues in certain vascular plants (e.g., the flax plants and cotton) are valuable raw materials used in the paper industry. Knowing which types of plants contain high fiber vascular tissues allows manufacturers to develop paper that is stronger and of a higher quality.

Finally, students randomly assigned to the neutral condition read a textbook chapter that did not add utility value. For example, after the same description about distinguishing between different groups of plants, the neutral manipulation was:

Because of their different structures, vascular plants store their own food and water while nonvascular plants do not. Therefore, there is a wider variety of plant groups that belong to vascular plants because nonvascular plants are restricted to growing in or around water.

Efforts were made to hold sentence structure and content as constant as possible, while at the same time selecting real and relevant connections for each condition. Several iterations of pilot testing were conducted to help ensure that manipulations were appropriate for each condition. All manipulations are provided in the Supplemental Material.

Post-Textbook Measures. After they read the textbook chapter, students' prosocial affordance beliefs were assessed again using the same scale (Pöhlmann, 2001) that was used at baseline in the participant pool background questionnaire. Responses were averaged $(\alpha=0.88)$.

Students' topic interest (i.e., interest toward the topic that they read about) was assessed with five items ("Please indicate how much you disagree or agree by selecting an option: Plant diversity is interesting; It is a waste of time to learn about plant diversity [reverse-coded]; Plant diversity fascinates me; I become very absorbed when reading about plant diversity; Plant diversity does not hold my attention at all [reversecoded]") on scales ranging from 1 (strongly disagree) to 7 (strongly agree). Responses were averaged $(\alpha=0.90)$. These items were modeled from Linnenbrink-Garcia et al. (2010).

Students' perceived competence with the reading material was measured with one item ("How well do you expect to perform on the quiz today"?). Students responded using a fivepoint Likert scale from 1 (not well at all) to 5 (extremely well). This item was modeled from Thoman and Sansone (2016).

Students took a short quiz to assess their understanding of the reading material. The tested material was the same for all students and was not related to any of the prosocial utility value connections-that is, the questions were only drawn from the content that was present in all three conditions. There were nine multiple-choice questions, each with four possible answers. An example question was: "Seed plants can be divided into two groups: gymnosperms and angiosperms. How are these two groups different?," and possible answers were: “(a) Gymnosperms have enclosed chambers where seeds can mature, while angiosperms do not, (b) gymnosperms have extensive vascular structures, while angiosperms do not, (c) gymnosperms have roots that anchor them, while angiosperms do not, or (d) none of the above." Correct responses were summed to create a quiz score, with higher values indicating more correct answers. All survey scales and quiz questions are provided in the Supplemental Material.

\section{Results}

Descriptive statistics of all study variables and correlations are presented in Table 1, and descriptive statistics of study variables by condition are shown in Table 2 . First, we checked whether random assignment into conditions was successful by testing whether students in the prosocial utility value, general utility value, and neutral conditions had similar levels of baseline prosocial affordance beliefs and baseline topic interest. There were no statistical differences between students' baseline affordance beliefs $(F(2,192)=0.79, p=0.454)$ or their baseline interest in the science topic $(F(2,192)=0.73, p=0.483)$ as a function of which condition they were in. Therefore, random assignment into conditions was successful. We used baseline prosocial affordance beliefs and baseline interest as covariates in our analyses to control for slight differences and effectively evaluate changes in affordance beliefs and interest from pre- to postengagement with the textbook chapter.

Second, this study focused on interest as an outcome and not on performance or competence. We expected to find that the prosocial utility information in the textbooks would not have immediate effects on students' learning or competence in a single session (although other studies have shown boosts in performance when students engage with course material over longer periods of time; e.g., Hulleman and Harackiewicz, 2009). As expected, the manipulation of information in the textbook did not significantly affect students' learning, as indicated by their quiz scores $(F(2,192)=0.04, p=0.958)$. Whereas the textbook manipulation had no effect on actual competence (quiz scores), the manipulation appears to have had at least some effect on perceptions of competence $(F(2,192)=1.35$,

TABLE 1. Descriptive statistics and correlations of study variables ${ }^{\mathrm{a}}$

\begin{tabular}{|c|c|c|c|c|c|c|c|c|}
\hline Variable & Scale & $M$ & $S D$ & 1 & 2 & 3 & 4 & 5 \\
\hline 1. Baseline prosocial Affordance beliefs & $1-7$ & 4.23 & 1.22 & - & & & & \\
\hline \multicolumn{9}{|l|}{ After reading textbook } \\
\hline 3. Prosocial affordance beliefs & $1-7$ & 4.41 & 1.32 & $0.50 * * *$ & $0.35 * * *$ & - & & \\
\hline 4. Topic interest & $1-7$ & 4.01 & 1.31 & $0.38 * * *$ & $0.51 * * *$ & $0.58 * * *$ & - & \\
\hline 6. Quiz score & $0-9$ & 5.66 & 1.63 & 0.08 & $0.14 *$ & 0.07 & $0.16^{*}$ & $0.24 * * *$ \\
\hline
\end{tabular}

${ }^{a} N=195$. Asterisks indicate significant coefficients: ${ }^{*} p<0.05 ;{ }^{* *} p<0.01$; ${ }^{* * *} p<0.001$. 
TABLE 2. Descriptive statistics of variables by textbook condition ${ }^{a}$

\begin{tabular}{|c|c|c|c|c|c|c|}
\hline \multirow[b]{2}{*}{ Variable } & \multicolumn{2}{|c|}{ Prosocial utility } & \multicolumn{2}{|c|}{ General utility } & \multicolumn{2}{|c|}{ Neutral textbook } \\
\hline & $M$ & $S D$ & $M$ & $S D$ & $M$ & $S D$ \\
\hline \multicolumn{7}{|l|}{ Before reading textbook } \\
\hline Baseline topic interest & 4.08 & 1.48 & 3.84 & 1.69 & 4.18 & 1.56 \\
\hline \multicolumn{7}{|l|}{ After reading textbook } \\
\hline Prosocial affordance beliefs & 4.82 & 1.26 & 4.20 & 1.35 & 4.10 & 1.27 \\
\hline Perceived competence & 2.46 & 0.86 & 2.60 & 0.76 & 2.69 & 0.88 \\
\hline Quiz score & 5.55 & 1.80 & 5.64 & 1.85 & 5.61 & 1.56 \\
\hline
\end{tabular}

${ }^{\mathrm{a}} \mathrm{N}=195$.

TABLE 3. ANCOVA comparisons of conditions on prosocial affordances and topic interest ${ }^{\mathrm{a}}$

\begin{tabular}{|c|c|c|c|c|c|c|c|}
\hline \multirow[b]{3}{*}{ Condition } & \multirow[b]{3}{*}{$n$} & \multicolumn{3}{|c|}{ Prosocial affordance beliefs } & \multicolumn{3}{|c|}{ Topic interest } \\
\hline & & & \multicolumn{2}{|c|}{ Tukey's HSD comparisons } & \multirow[b]{2}{*}{ Mean } & \multicolumn{2}{|c|}{ Tukey's HSD comparisons } \\
\hline & & Mean & Prosocial utility & General utility & & Prosocial utility & General utility \\
\hline Prosocial utility & 78 & $\begin{array}{c}4.80 \\
(1.11)\end{array}$ & & & $\begin{array}{c}4.26 \\
(1.08)\end{array}$ & & \\
\hline General utility & 55 & $\begin{array}{c}4.26 \\
(1.11)\end{array}$ & 0.007 & & $\begin{array}{c}3.86 \\
(1.08)\end{array}$ & 0.037 & \\
\hline Neutral & 62 & $\begin{array}{c}4.07 \\
(1.10)\end{array}$ & $<0.001$ & 0.339 & $\begin{array}{c}3.84 \\
(1.07)\end{array}$ & 0.025 & 0.928 \\
\hline
\end{tabular}

${ }^{\mathrm{a}}$ Means for prosocial affordance beliefs are adjusted to control for perceived competence and baseline prosocial affordance beliefs. Means for topic interest are adjusted to control for perceived competence and baseline topic interest. Values in parentheses indicate standard deviations. Tukey's HSD (honestly significant difference) comparisons are $p$ values adjusted for multiple comparisons.

$p=0.262$ ). We report further results with perceived competence later in the Exploratory Analyses section. To isolate the effects of the prosocial utility information on students' interest and affordance beliefs, we controlled for perceived competence across analyses. ${ }^{1}$

Did Students Who Read the Prosocial Textbook Report Greater Prosocial Affordance Beliefs? We conducted a oneway (textbook condition: prosocial utility value, general utility value, neutral) between-subjects analysis of covariance (ANCOVA) with prosocial affordance beliefs as the outcome variable and perceived competence and baseline prosocial affordance beliefs as covariates. Perceived competence $(F(1$, $190)=8.38, p=0.004)$ and baseline prosocial affordance beliefs $(F(1,190)=47.34, p<0.001)$ were significant predictors of students' prosocial affordance beliefs after they engaged with the textbooks. Supporting our hypothesis, there was a significant effect of textbook condition on prosocial affordances, $F(2,190)=8.11, p<0.001$, controlling for perceived competence and baseline prosocial affordances. Post hoc tests (see Table 3) revealed that those in the prosocial utility value condition reported greater beliefs that the chapter topic affords opportunities to fulfill prosocial goals than those in the general utility value $(d=0.20)$ and neutral conditions $(d=0.28)$. The general utility value and neutral conditions did not differ

\footnotetext{
${ }^{1}$ We also measured students' previous familiarity with the textbook chapter, because the experimental materials were adapted from a real science textbook used in real courses. However, previous familiarity with the textbook was not associated with any of the dependent variables and was removed from all analyses.
}

$(d=0.07)$. Results were unchanged even when the covariates were not included in the model.

Did Students Who Read the Prosocial Textbook Report Greater Interest in the Science Topic? We conducted a oneway (textbook condition: prosocial utility value, general utility value, neutral) between-subjects ANCOVA with topic interest as the outcome variable and perceived competence and baseline interest as covariates. We controlled for perceived competence, because interest and perceptions of competence (or the similar construct, self-efficacy) have been frequently confounded in prior work (e.g., Morgan et al., 2001; Diekman et al., 2010; Hulleman et al., 2010; Sansone et al., 2012; Thoman and Sansone, 2016; Bian et al., 2018). Perceived competence $(F(1,190)$ $=20.40, p<0.001)$ and baseline interest $(F(1,190)=53.42$, $p<0.001$ ) were strong predictors of interest in the topic after students engaged with the textbooks. Supporting our hypothesis, there was a significant effect of textbook condition on topic interest, controlling for perceived competence and baseline interest, $F(2,190)=3.34, p=0.038$. Post hoc tests (see Table 3 ) revealed that those in the prosocial utility value condition reported greater topic interest than those in the general utility value $(d=0.15)$ and neutral $(d=0.16)$ conditions. The general utility value and neutral conditions did not differ $(d=0.01)$.

It should be noted that the effect of textbook condition on topic interest did not reach statistical significance when perceived competence was removed from the model, $F(2,191)=$ 1.94, $p=0.147$, although effect size estimates of the mean differences between the prosocial utility and the two other conditions $(d=0.12 ; d=0.12)$, respectively, were very similar 
to those derived from the initial analysis. The effect size for the general utility and neutral comparison $(d=0.00)$ was also similar to that reported when perceived competence was controlled for. To test whether perceived competence moderated the effect of condition on interest (e.g., Durik et al., 2015), we conducted a multiple regression analysis using dummy codes with the prosocial condition as the reference group. The results of the regression model indicated that perceived competence was not a moderator when comparing the prosocial utility value and general utility value conditions $(b=-0.11, \mathrm{SE}=0.24, p=0.642)$ or the prosocial utility value and neutral conditions $(b=0.04$, $\mathrm{SE}=0.21, p=0.864$ ), controlling for baseline interest.

Was the Effect of Textbook Condition on Topic Interest Mediated by Increases in Prosocial Affordance Beliefs? Because the two control conditions (i.e., general utility value, neutral) did not differ on critical variables (e.g., prosocial affordance beliefs, topic interest), we combined them into one control group for model parsimony in subsequent analyses. Those who read the prosocial textbook were coded as 1 , whereas those who read either of the control textbooks (i.e., general utility value, neutral) were coded as 0 .

To test for mediation, we conducted path analysis on Mplus (v. 7) using bootstrap estimation of 10,000 samples. As shown in Figure 1, the total indirect effect of the prosocial textbook (vs. controls) on interest was positive and statistically significant ( $b=$ $0.26, \mathrm{SE}=0.08, p=0.001,95 \% \mathrm{CI}[0.13,0.44]$ ), which indicated that changes in prosocial affordance beliefs mediated the effect of the textbook condition on interest. The direct effect of textbook condition on interest was no longer significant, suggesting full mediation. Students randomly assigned to read the prosocial textbook (compared with those who read the control textbooks) reported greater beliefs that the topic afforded opportunities to fulfill prosocial goals, which in turn led to greater interest in the science topic.

Next, we reran the model as a multiple group comparison to test for differences in model effects (see Supplemental Material for descriptive statistics by condition and racial/ethnic group). Results are shown in Table 4. For URM and white students, the effect of the prosocial textbook (compared with controls) on changes in prosocial affordance beliefs was statistically significant, controlling for perceived competence and baseline prosocial affordance beliefs. The coefficients were statistically different (Wald $\chi^{2}=4.31, d f=1, p=0.038$ ). This analysis indicates that both URM and white students who read the prosocial textbook (vs. the control textbooks) reported greater beliefs that the science topic afforded prosocial opportunities-but URM students reported greater increases in these beliefs compared with white students. For Asian students, the effect of the prosocial textbook (compared with controls) did not reach statistical significance. This coefficient was also statistically different from the coefficient in the URM model (Wald $\chi^{2}=4.71, d f=1, p=$ 0.030), which indicates that the effect of the prosocial textbook (vs. controls) on changes in prosocial affordance beliefs was greater for URM students than it was for Asian students.

Next, the effect of prosocial affordance beliefs on interest was statistically significant for all students, controlling for perceived competence, textbook condition, and baseline interest. The coefficient for URM students $(b=0.57)$ was considerably larger than the coefficients for white $(b=0.30)$ and Asian $(b=$ 0.27) students, but coefficient comparison tests between URM and white students (Wald $\chi^{2}=3.47, d f=1, p=0.063$ ) and URM and Asian students (Wald $\chi^{2}=3.45, d f=1, p=0.063$ ) did not reach statistical significance. Put together, the total indirect effect of the prosocial textbook (vs. controls) on interest was positive and statistically significant for URM students and white students, which indicated that changes in prosocial affordance beliefs mediated the effect of the textbook condition on interest. However, the total indirect effect was positive but did not reach statistical significance for Asian students.

We also tested whether the model differed by gender. The effect of the prosocial textbook (compared with controls) on changes in prosocial affordance beliefs did not differ by gender for women $(b=0.59, \mathrm{SE}=0.18, p=0.001)$ and men $(b=$ $0.53, \mathrm{SE}=0.34, p=0.123$; Wald $\chi^{2}=0.03, d f=1, p=0.869$ ), controlling for perceived competence and baseline prosocial affordance beliefs. Although the effect for men did not reach statistical significance, the coefficient is nearly identical to

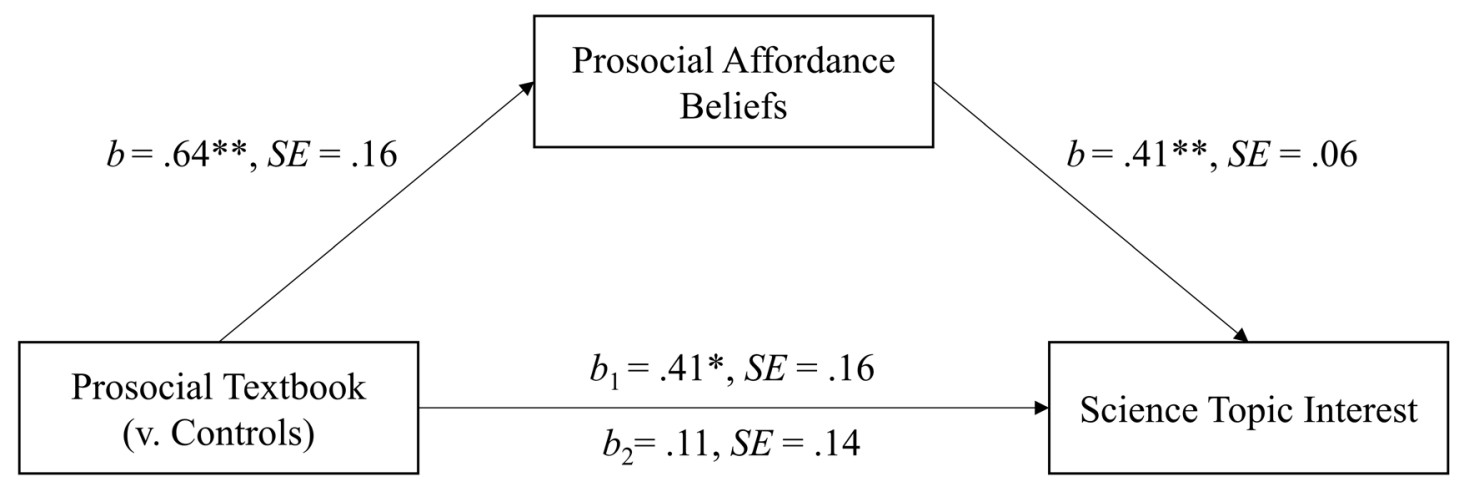

FIGURE 1. Mediation model of textbook condition predicting interest through prosocial affordance beliefs. The path from prosocial textbook to prosocial affordance beliefs controls for perceived competence and baseline prosocial affordance beliefs. The path from prosocial affordance beliefs to interest controls for perceived competence and baseline interest. Along the bottom, the $b_{1}$ value indicates the effect without the mediator included in the model, and the $b_{2}$ value indicates the effect with the mediator included in the model. Asterisks indicate significant coefficients $\left({ }^{*} p<0.01 ;{ }^{* *} p<0.001\right)$. 
TABLE 4. Multiple group comparison tests of prosocial affordances as a mediator of textbook condition and topic interest ${ }^{\mathrm{a}}$

\begin{tabular}{|c|c|c|c|c|c|c|}
\hline \multirow[b]{2}{*}{ Predictor } & \multicolumn{2}{|c|}{ URM $(n=65)$} & \multicolumn{2}{|c|}{ Asian $(n=49)$} & \multicolumn{2}{|c|}{ White $(n=80)$} \\
\hline & $b$ & SE & $b$ & SE & $b$ & SE \\
\hline \multicolumn{7}{|c|}{ Prosocial affordances as dependent variable } \\
\hline Prosocial textbook & $1.22 * * *$ & 0.29 & 0.29 & 0.32 & $0.47 *$ & 0.21 \\
\hline Baseline prosocial affordances & $0.52 * * *$ & 0.14 & $0.47^{* * *}$ & 0.16 & $0.38 * * *$ & 0.10 \\
\hline Perceived competence & 0.27 & 0.19 & -0.06 & 0.17 & $0.53 * * *$ & 0.14 \\
\hline \multicolumn{7}{|l|}{ Topic interest as dependent variable } \\
\hline Prosocial affordances & $0.57 * * *$ & 0.11 & $0.27^{*}$ & 0.13 & $0.30 * *$ & 0.10 \\
\hline Prosocial textbook & 0.17 & 0.27 & 0.29 & 0.30 & -0.13 & 0.22 \\
\hline Baseline topic interest & $0.20 *$ & 0.10 & $0.31^{* * *}$ & 0.10 & $0.33 * * *$ & 0.07 \\
\hline Perceived competence & 0.22 & 0.14 & $0.44 * *$ & 0.20 & $0.26 *$ & 0.12 \\
\hline Total indirect effects & $0.69 * *$ & 0.24 & 0.08 & 0.10 & $0.14 *$ & 0.07 \\
\hline
\end{tabular}

aProsocial textbook (prosocial utility textbook $=1$, general utility/neutral textbook $=0$ ). Asterisks indicate significant coefficients $\left({ }^{*} p \leq 0.05 ; * * p<0.01 ; * * * p<0.001\right.$ ). $N=194$. One participant was excluded from analyses because that student did not fall into the URM, Asian, or white categories. Total indirect effects: URM $95 \%$ CI [0.32, 1.25]; Asian 95\% CI [-0.07, 0.33); white 95\% CI [0.03, 0.35].

the coefficient for women, and the larger standard error is likely due to smaller sample size $(-30 \%$ were men). For the second path, there were also no gender differences in the effect of prosocial affordance beliefs on topic interest among women $(b=0.40, \mathrm{SE}=0.07, p<0.001)$ and men $(b=0.39$, $\mathrm{SE}=0.12, p=0.001$; Wald $\left.\chi^{2}=0.01, d f=1, p=0.946\right)$, after controlling for perceived competence, textbook condition, and baseline interest.

Exploratory Analyses: Effects of Textbook Condition on Perceptions of Competence. Although study predictions focused on interest, we also tested for the effect of condition on perceived competence, while controlling for interest. We found a marginally significant effect on perceived competence, $F(2$, $191)=2.95, p=0.055$. Students in the prosocial utility condition $(M=2.41, S D=0.79)$ reported lower perceptions of competence compared with the neutral condition $(\mathrm{M}=2.71, \mathrm{SD}=$ 0.78), $p=0.025$. The comparison between the prosocial utility condition and the general utility condition $(\mathrm{M}=2.65, \mathrm{SD}=$ 0.78 ) did not reach statistical significance, but it was close $(p=$ $0.078)$. The neutral and general utility conditions did not differ $(p=0.696)$. We also tested for effects on quiz scores, controlling for interest, but results of this model $(F(2,191)=0.19, p=$ 0.831 ) were virtually unchanged compared with the model without controlling for interest. Motivation researchers have often focused on interest while controlling for perceived competence (e.g., Sansone, 1989; Losier and Vallerand, 1994), but they have typically not done the reverse. Our pattern of results suggests that, in addition to considering the effect of perceived competence on interest, researchers may also want to explore how interest affects competence beliefs.

\section{Discussion}

The purpose of study 1 was to test whether science textbooks can be used as tools to reframe science stereotypes toward cultivating beliefs that science offers opportunities to fulfill prosocial goals. Randomly assigning students to read a textbook chapter that highlighted the prosocial utility value of the topic enhanced students' prosocial affordance beliefs above and beyond their competence perceptions and initial affordance beliefs compared with students who read the control textbooks (one that highlighted general utility value and one that did not add utility value information). The prosocial utility information in the textbook chapter also increased students' interest in the science topic. The increases in topic interest occurred indirectly through changes in students' prosocial affordance beliefs. Therefore, evidence from study 1 supports the notion that textbooks may be effective tools to change beliefs about the nature and value of scientific work to promote science interest.

Study 1 also tested two ways that prosocial affordance beliefs may shape interest differently for groups of people. One way groups may differ is in the extent to which prosocial affordance beliefs influence interest (e.g., Thoman et al., 2015, 2019). Our results revealed no statistical differences by gender or ethnic group, such that affordance beliefs positively influenced interest for all students (i.e., no differences in valuation of prosocial goals). However, it is worthwhile to note that the coefficient for URM students $(b=0.57)$ was nearly twice as large as the coefficients for Asian $(b=0.27)$ and white $(b=$ 0.30) students, and comparison tests were marginally significant (both $p=0.063$ ). There is a need for further research with larger samples and greater statistical power to examine ethnic group differences in valuation of prosocial goals.

Another way groups may differ is in the extent to which their affordance beliefs are sensitive to cues that signal the presence or absence of opportunities to fulfill prosocial goals (i.e., difference in perception of prosocial goals). Consistent with this possibility, we found that URM students who read the prosocial textbook reported statistically greater increases in prosocial affordance beliefs compared with both white and Asian students. This effect was still positive and statistically significant for white students. The effect for Asian students was comparable to that of white students, but the standard error for Asian students was high, likely reflecting the heterogeneity of the students classified as Asian/Asian American in this sample (cf. Thoman et al., 2015), resulting in a nonsignificant effect.

Finally, there was some evidence to suggest that students who read the prosocial textbook experienced lower perceptions of competence when compared with the neutral condition ( $p=$ 0.025 ), and potentially when compared with the general utility condition ( $p=0.078$ ) as well, even though they also found the text most interesting. Although we did not predict this pattern a priori, one explanation could be that the prosocial utility value manipulations contained more complex ideas than the other two 
textbook versions. Considering Bloom's taxonomy (Bloom et al., 1956; Anderson et al., 2001), for example, the prosocial utility value manipulations can be thought of as information that requires deeper conceptual understanding, rendering the prosocial utility information to be perceived as more difficult than the additional factual information that was in the neutral condition. The level of difficulty of the manipulations was not reflected in the quiz score, because we only asked questions about the science concepts-and not the prosocial connections-in order to compare learning across conditions. This explanation would be consistent with prior work, which suggests that a task can be more interesting (and thereby promote greater cognitive resources) even when it is more difficult than a comparable boring task (Thoman et al., 2011). Because this pattern for perceived competence was not expected, we do not know how confident we should be in a replication of this effect. Nonetheless, it points to an important direction of effects, such that effects on achievement-related constructs (e.g., perceived competence and performance) may not always be in the same direction as effects on interest (Sansone, 2009; Sansone et al., 2012). Though undoubtedly complex, future research should continue to investigate and disentangle the relationships among performance, competence perceptions, and interest in biology education.

\section{STUDY 2: LANDSCAPE ANALYSIS OF PROSOCIAL UTILITY VALUE IN REAL SCIENCE TEXTBOOKS}

The purpose of study 2 was to conduct a brief landscape analysis of whether and how prosocial utility value content is currently presented in popular science textbooks. The findings from study 1 suggested benefits in students' exposure to prosocial utility value content in textbooks for shaping prosocial affordance beliefs and science interest. This study follows these findings by attempting to gauge whether students might have opportunities to be exposed to this type of content through real science textbooks in their courses. Textbooks selected from introductory undergraduate science courses were descriptively coded for the presence and placement of prosocial utility value content. If this type of content was present in science textbooks, we sought to understand patterns of where and how it was presented.

\section{Methods}

Nine science textbooks (three biology, three chemistry, and three physics) were coded for the presence of prosocial utility value content. To ensure that textbooks were current, we used textbooks listed by faculty for introductory biology, chemistry, and physics courses at two southern California universities. We chose these specific textbooks, because they were described as "best-selling" on publisher websites (e.g., Tro, 2010; Reece et al., 2014) and more objectively described as being used (e.g., "[The textbook] is in use in large engineering and science courses at large and medium sized universities"; Chabay and Sherwood, 2011). The selected textbooks were divided into chapters (e.g., "Structure and Function of Plasma Membranes"), and most chapters included three sections: an introduction to the chapter (i.e., usually one or two pages of content at the beginning that introduced the chapter topic), the body (i.e., the middle section that made up most of the textbook and presented the scientific content), and conclusion (i.e., several pages at the end of the chapter that usually contained a summary of key concepts and practice problems).
We randomly sampled pages from each textbook to code. To ensure that our page samples were representative of the whole textbook, we coded sections from each chapter. More specifically, for each chapter in the textbooks, we coded all introduction pages, a random sample from the body (three consecutive pages for shorter chapters [ 25 pages]; five consecutive pages for longer chapters [ $\sim 50$ pages]), and all pages in the conclusion. Each page was individually coded on several characteristics (e.g., location on the page) to understand where and how prosocial utility value was presented in the textbooks relative to other types of content. On average, 160 pages per textbook (more than 1500 total pages across the books) were coded.

Pages were coded for the presence of explicit prosocial utility value content. Research assistants were trained to code textbook prosocial utility value content, which was defined in the coding manual as "Any value or relevant connection that an individual finds that enables them to complete a potential, present, or future goal that is related to helping a community or a group of people." Examples provided to coders included: "Using this new technology, we can establish the innocence of people who have been wrongly convicted of murder and other capital crimes" and "Heavy metals (including lead and mercury) are persistent in the environment and have serious health consequences for people. Green algae have the ability to bind to these heavy metal toxins, allowing them to be safely excreted from the body and improving health." Research assistants were instructed to not code content that may only implicitly be related to helping a community or group of people. For example, content where science was applied to advancing knowledge about a disease but did not directly convey the benefits for people (e.g., the potential to contribute to their health) was not coded as prosocial. Therefore, content was only coded as prosocial utility value when the topic or concept was explicitly stated to be used for helping people.

Once a prosocial utility value connection was identified, it was coded on the following characteristics. Chapter location captured where the prosocial utility value content was located within the chapter to gauge where prosocial utility value content is typically located. The options were: the introduction, the body, and the conclusion. Similarly, page location captured where the prosocial utility value content was located within the page. The options were: in the text (i.e., inside main paragraphs on the page), sidebar (i.e., on the side column of text often found on pages), or figures (e.g., as a part of a figure description). Text density on the page was coded in order to understand the presentation of the pages where prosocial content may be located. The options were: mostly text (i.e., the page primarily consisted of paragraphs) or mostly non-text (i.e., the page primarily consisted of pictures or figures). Finally, because prosocial utility value in textbooks can be emphasized using a question, the prosocial content was also coded for whether or not it was framed as a part of a question.

Research assistants found the coding guide and rules to be straightforward and easy to use. During the practice phase of our training, all students reached agreement on coding practice chapters by their second try. Research assistants were instructed to be inclusive of any text that described how science can be used to help others. Moreover, if research assistants were unsure about whether something could be a prosocial utility value connection, those items were discussed with senior authors 
(J.Z., G.A.L.) or discussed by the group during lab meetings. The coding guide is available in the Supplemental Material.

\section{Results}

Of the 1551 textbook pages that were examined, only $20(\sim 1 \%)$ contained identifiable prosocial utility value content. Of note, nearly all connections were found in biology textbooks (19 in biology, 1 in physics, 0 in chemistry). The location of the content, including placement within the chapter and on the page, varied. The prosocial utility value content was located mostly in the conclusion areas of the chapter $(12$; on $4 \%$ of 296 conclusion pages) compared with the body areas $(5$; on $<1 \%$ of 1013 body pages) and introduction areas (3; on 1\% of 242 introduction pages). The prosocial content was primarily found in the text (18) rather than in sidebar (1) or figure (1) areas of the pages. Examination of the text density of the pages indicated that the pages that had prosocial content were mostly composed of text (17) compared with non-text (3). Most prosocial content was not framed as a part of a question (16) compared with being part of a question (4).

To illustrate how textbooks connected science topics to directly helping humans, one identified example from the coded textbooks was: "The equation also has medical applications, such as estimating the percentage of population carrying the allele for an inherited disease. For example, consider phenylketonuria (PKU), a metabolic disorder that results from homozygosity for a recessive allele and occurs in about one out of every 10,000 babies born in the United States. Left untreated, PKU results in mental disability and other problems" (Reece et al., 2014, p. 486). An identified example of how the prosocial content was framed as part of a question was: "Today, it is possible for a diabetic patient to purchase human insulin from a pharmacist. What technology makes this possible and why is it a benefit over how things used to be?" (Fowler et al., 2013, p. 247).

\section{Discussion}

In study 2, we aimed to understand whether and how prosocial utility value was included and presented in real science textbooks. As demonstrated in study 1, the presence of prosocial utility value content can benefit students, yet in this study, we found that there would be few opportunities for students to find explicit prosocial connections in their science textbooks. In the more than 1500 pages examined, 1\% (20 pages) contained prosocial content. The books selected for this study were textbooks that were assigned in introductory science courses, and as such, they represent content that students may be exposed to early in their undergraduate science courses-the point at which STEM attrition is highest. A lack of prosocial content in these textbooks is reflective of common beliefs that the culture of science is socially isolated and esoteric, which can influence college students' science motivation (Cheryan et al., 2015). Additionally, the identified prosocial content was almost exclusively found in biology textbooks, which may be unsurprising, given that biology has been considered to be more prosocial than physics (Bruun et al., 2018) and possibly other physical science fields.

Although it was challenging to make generalizations about how prosocial utility value content is represented in textbooks with the few examples we found, there were some patterns. In terms of the location and characteristics of prosocial content, we found that it was primarily located at the end of the chapters. In general, most content being located at the end of a chapter may indicate that it is presented after a majority of topical information. Study 1 demonstrated that prosocial content may serve to change affordance beliefs and bolster students' interest, but it is unclear whether reading about it before or after additional content would be most beneficial. Additionally, we found that these excerpts were mostly located in the text (rather than as part of a figure) and were not usually presented as a question. How textbooks convey what is valued and important in science fields needs further examination. For example, science texts should be analyzed on a deeper level by investigating their epistemological foundations and assumptions. Are the ways of knowing and doing science multicultural (Harding, 1994)? Are they gendered (Harding, 2016)? Such analysis would provide a more nuanced understanding of the science culture being communicated through science texts, above and beyond our brief analysis of goal affordance opportunities.

\section{GENERAL DISCUSSION}

Seeing the value of science is a critical component for understanding student interest and participation in STEM (Boucher et al., 2017), especially in the earlier stages of students' undergraduate careers, when they are still forming their impressions of scientific work. Even after taking into account students' perceptions of competence, initial affordance beliefs, and initial interest, our findings support the idea that highlighting the prosocial utility of science in textbooks can change beliefs about the nature and value of science. Across two studies, our findings demonstrated that: 1) prosocial affordance beliefs matter for science interest; 2) textbooks can be used to change prosocial affordance beliefs; 3) widely used science texts are currently missing opportunities to emphasize the prosocial utility value of science; and 4) URM students may particularly benefit from shifting representations of the sciences as prosocial fields.

In study 1 , we found that students who engaged with a prosocial utility biology textbook chapter reported greater prosocial affordance beliefs and greater interest than those who engaged with general utility and neutral biology textbook chapters. However, study 2 found that biology textbooks contained more prosocial utility value information than other science disciplines (i.e., chemistry and physics). The fact that we tested the effectiveness of prosocial utility value connections in a discipline that may already be perceived as more prosocial than other science disciplines suggests that our study represents a conservative test of the effectiveness of prosocial utility value in textbooks. Therefore, we would expect larger effects in chemistry, physics, and other STEM disciplines, such as engineering and computer science. Replication of this study in other subjects could further our understanding of the robustness of prosocial utility value connections across disciplinary lines.

In contrast to the pattern of results for URM students, results for Asian students were inconsistent. Prosocial affordance beliefs did significantly predict interest for these students, suggesting that they do value prosocial goals, but our textbook manipulation in study 1 did not significantly change their affordance beliefs. The effect estimate for Asian students was positive, but the variability was greater than for URM and white students, rendering the effect nonsignificant. Though difficult 
to pinpoint why this happened, we suspect that it could be due to lower power for this group, given that the Asian group had the smallest sample size compared with the URM and white groups. Another explanation may be that Asian students are a particularly heterogeneous group in our sample, and there are important differences in the lived experiences and the salience of certain goals between Southeast Asian and East Asian students (Nguyen et al., 2015). The large variability for this group is consistent with other studies (e.g., Thoman et al., 2017), and this suggests that a more nuanced understanding of racial minority and majority groups is needed.

We detected group differences by race/ethnicity, such that URM students' heightened prosocial goal orientations may make prosocial cues more cognitively accessible. That is, URM students' affordance beliefs were more sensitive to cues that signaled the presence of prosocial information. This points to a group difference in perception, such that efforts to change the science culture will likely be most recognized among URM students. Although we did not find ethnic group differences in valuation (i.e., prosocial affordances predicted interest for all students), the effect among URM students was markedly larger than for Asian and white students, and the statistical comparison tests were marginally significant. Future research should continue to explore racial/ethnic group differences in valuation of prosocial goals with larger sample sizes.

We did not detect gender differences, as found in other studies (e.g., Clark et al., 2016). Both men and women experienced similar changes in prosocial affordance beliefs after engaging with the textbook that highlighted prosocial utility value, and both experienced greater subsequent interest. When measured through self-reports, many studies suggest that women's reported communal values or affordance beliefs tend to predict greater interest, but when manipulated as part of content with added communal information, communal affordances seem to be beneficial for both women and men (e.g., Brown et al., 2015a). This issue is ripe for further work to examine whether inconsistencies in gender differences across studies are related to measurement, to the types of outcomes being studied (e.g., career interest vs. interest in a specific topic), or to the contexts in which studies take place. We did not have the statistical power to test for intersectional effects by gender and race/ethnicity. Future research should also explore whether affordance beliefs influence interest development differently for students with varying intersections of social identities (e.g., race, ethnicity, gender, social class).

This research ties together several theoretical frameworks, including goal congruity theory (Diekman et al., 2010), expectancy-value theory (Eccles and Wigfield, 2002), and culturally relevant teaching (Aronson and Laughter, 2016). What is clear from this study, and from theoretical and research literatures, is that affordance beliefs matter for science interest and participation. To counter the robust stereotypes that science fields are not prosocial and to sustain interest in science at this critical stage when attrition is highest, researchers, educators, and educational leaders need a variety of tools. As this study has demonstrated, science texts powerfully convey what kind of work is important within a particular field, which could help change the science culture. Adding value content and prosocial examples to science lectures should also help, but directly communicated connections from instructors are not enough on their own
(Canning and Harackiewicz, 2015; Curry et al., 2019). Utility value interventions do show that having students make personalized connections through writing essays are effective for increasing science interest and other motivation and achievement outcomes (e.g., Harackiewicz et al., 2016; Tibbetts et al., 2016). Changing textbooks, however, may be especially important, because they have a wide reach. Whereas essay and lecture interventions would require buy-in from all instructors, because individual instructors control course lectures and assignments, highlighting prosocial utility value in science textbooks can have far-reaching implications for students across the sciences. Moreover, traditional utility value work has focused on individual value connections (e.g., How is this topic useful for me?), whereas changing textbooks focuses on normative beliefs about the opportunities and affordances that a field provides (e.g., What kind of opportunities are available here?, Is this a helping field?). Both of these are important, but they are distinct mechanisms for promoting science career interest and retention. Therefore, we expect that prosocial information in science texts would be maximally effective when combined with additional strategies, and this question is open for future work.

\section{CONCLUSION}

Although stereotypes about STEM fields as lacking prosocial opportunities are pervasive, there are many ways that scientists and science students do and could help others, give back to communities, and tend to the needs of others through scientific work. Stereotypes are notoriously difficult to change (e.g., Weber and Crocker, 1983), but the goal affordance perspective provides a pathway for changing normative beliefs about the culture of science to reflect that scientists value working with and helping others (Diekman et al., 2010). In particular, highlighting the many ways that science can be used to help others promotes interest in science majors and careers. Evidence from our studies suggests that this strategy is beneficial for all students but may be especially beneficial for broadening participation among African-American, Latino, and Native American students, who continue to be underrepresented in the sciences. Researchers, educators, curriculum designers, and policy makers should, therefore, emphasize the prosocial utility value of science in STEM environments and curricula to allow students to not only see and learn about how they can help people but to also allow them to do so in reality and practice.

\section{ACKNOWLEDGMENTS}

We thank research assistants from the Motivation and Social Identity Lab for their assistance in data collection and coding. We also thank science professors Tom Huxford, Matt Anderson, John Love, and Leroy McClenaghan from San Diego State University for loaning or donating their textbooks to us, and we thank monitoring editor Sarah L. Eddy and two anonymous reviewers for their thoughtful feedback on this article. Data collected for this study and preparation of this article were supported in part by the Chancellor's Doctoral Incentive Program (California State University, Office of the Chancellor); Associated Students Inc. Student Research Funds from California State University, Long Beach; and grant DRL-1622991 from the NSF. Any opinions, findings, and conclusions or recommendations expressed in this material are our own and do not necessarily reflect the views of the NSF. 


\section{REFERENCES}

Abele, A. E., \& Wojciszke, B. (2007). Agency and communion from the perspective of self versus others. Journal of Personality and Social Psychology, 93, 751-763. doi: 10.1037/0022-3514.93.5.751

Almatrafi, O., Johri, A., Rangwala, H., \& Lester, J. (2017). Retention and persistence among STEM Students: A comparison of direct admit and transfer students across engineering and science. Paper presented at the American Society for Engineering Education Annual Meeting, Columbus, $\mathrm{OH}$.

Anderson, L. W., Krathwohl, D. R., \& Bloom, B. S. (2001). A taxonomy for learning, teaching, and assessing: A revision of Bloom's taxonomy of educational objectives. New York: Longman.

Aronson, B., \& Laughter, J. (2016). The theory and practice of culturally relevant education: A synthesis of research across content areas. Review of Educational Research, 86(1), 163-206.

Berkowitz, L., \& Donnerstein, E. (1982). External validity is more than skin deep: Some answers to criticisms of laboratory experiments. American Psychologist, 37(3), 245-257.

Bian, L., Leslie, S. J., Murphy, M. C., \& Cimpian, A. (2018). Messages about brilliance undermine women's interest in educational and professional opportunities. Journal of Experimental Social Psychology, 76, 404-420.

Bloom, B. S., Krathwohl, D. R., \& Masia, B. B. (1956). Taxonomy of educational objectives: The classification of educational goals. New York: D. McKay.

Boucher, K. L., Fuesting, M. A., Diekman, A. B., \& Murphy, M. C. (2017). Can I work with and help others in this field? How communal goals influence interest and participation in STEM fields. Frontiers in Psychology, 8, 901.

Brinkman, W. B., \& Diekman, A. B. (2016, March 2-5). Applying the communal goal congruity perspective to enhance diversity and inclusion in undergraduate computing degrees. Paper presented at the ACM Technical Symposium on Computer Science Education (Memphis, TN). doi: $10.1145 / 2839509.2844562$

Brown, E. R., Smith, J. L., Thoman, D. B., Allen, J. M., \& Muragishi, G. (2015a). From bench to bedside: A communal utility value intervention to enhance students' biomedical science motivation. Journal of Educational Psychology, 107(4), 1116-1135. doi: 10.1037/edu0000033

Brown, E. R., Steinberg, M., Lu, Y., \& Diekman, A. B. (2018). Is the lone scientist an American dream? Perceived communal opportunities in STEM offer a pathway to closing US-Asia gaps in interest and positivity. Social Psychological and Personality Science, 9(1), 11-23.

Brown, E. R., Thoman, D. B., Smith, J. L., \& Diekman, A. B. (2015b). Closing the communal gap: The importance of communal affordances in science career motivation. Journal of Applied Social Psychology, 45(12), 662673.

Bruun, M., Willoughby, S., \& Smith, J. L. (2018). Identifying the stereotypical who, what, and why of physics and biology. Physical Review Physics Education Research, 14(2), 020125.

Canning, E. A., \& Harackiewicz, J. M. (2015). Teach it, don't preach it: The differential effects of directly-communicated and self-generated utility-value information. Motivation Science, 1(1), 47-71.

Chabay, R. W., \& Sherwood, B. A. (2011). Matter and interactions (3rd ed.). Hoboken, NJ: John Wiley and Sons.

Chamany, K., Allen, D., \& Tanner, K. (2008). Making biology learning relevant to students: Integrating people, history, and context into college biology teaching. CBE-Life Sciences Education, 7(3), 267-278.

Cheryan, S., Master, A., \& Meltzoff, A. N. (2015). Cultural stereotypes as gatekeepers: Increasing girls' interest in computer science and engineering by diversifying stereotypes. Frontiers in Psychology, 6, 1-8.

Clark, E. K., Fuesting, M. A., \& Diekman, A. B. (2016). Enhancing interest in science: Exemplars as cues to communal affordances of science. Journal of Applied Social Psychology, 46(11), 641-654.

Clump, M. A., Bauer, H., \& Bradley, C. (2004). The extent to which psychology students read textbooks: A multiple class analysis of reading across the psychology curriculum. Journal of Instructional Psychology, 31(3), 227-232.

Collard, D. M., Girardot, S. P., \& Deutsch, H. M. (2002). From the textbook to the lecture: Improving prelecture preparation in organic chemistry. Journal of Chemical Education, 79(4), 520.

Curry, K. W., Jr., Spencer, D., Pesout, O., \& Pigford, K. (2019). Utility value interventions in a college biology lab: The impact on motivation. Journal of Research in Science Teaching, doi: oRg/10.1002/tea.21592
Davidesco, I., \& Milne, C. (2019). Implementing Cognitive Science and Discipline-Based Education Research in the Undergraduate Science Classroom. CBE-Life Sciences Education, 18(3), es4.

Diekman, A. B., Brown, E. R., Johnston, A. M., \& Clark, E. K. (2010). Seeking congruity between goals and roles: A new look at why women opt out of science, technology, engineering, and mathematics careers. Psychological Science, 21(8), 1051-1057.

Diekman, A. B., Clark, E. K., Johnston, A. M., Brown, E. R., \& Steinberg, M. (2011). Malleability in communal goals and beliefs influences attraction to stem careers: Evidence for a goal congruity perspective. Journal of Personality and Social Psychology, 101(5), 902-918.

Diekman, A. B., Steinberg, M., Brown, E. R., Belanger, A. L., \& Clark, E. K. (2017). A goal congruity model of role entry, engagement, and exit: Understanding communal goal processes in STEM gender gaps. Personality and Social Psychology Review, 21(2), 142-175.

Durik, A. M., Shechter, O. G., Noh, M., Rozek, C. S., \& Harackiewicz, J. M. (2015). What if I can't? Success expectancies moderate the effects of utility value information on situational interest and performance. Motivation and Emotion, 39(1), 104-118

Eccles, J. S., \& Wigfield, A. (2002). Motivational beliefs, values, and goals Annual Review of Psychology, 53(1), 109-132.

Fowler, S., Roush, R., \& Wise, J. (2013). Concepts of biology (1st ed.). Houstin, TX: OpenStax College.

French, M., Taverna, F., Neumann, M., Paulo Kushnir, L., Harlow, J., Harrison, D., \& Serbanescu, R. (2015). Textbook use in the sciences and its relation to course performance. College Teaching, 63(4), 171-177.

Fryberg, S. A., \& Markus, H. R. (2007). Cultural models of education in American Indian, Asian American and European American contexts. Social Psychology of Education, 10(2), 213-246.

Fuesting, M. A., Diekman, A. B., \& Hudiburgh, L. (2017). From classroom to career: The unique role of communal processes in predicting interest in STEM careers. Social Psychology of Education, 20(4), 875896.

Gibbs, K. D., Jr., \& Griffin, K. A. (2013). What do I want to be with my PhD? The roles of personal values and structural dynamics in shaping the career interests of recent biomedical science PhD graduates. CBE-Life Sciences Education, 12(4), 711-723.

Harackiewicz, J. M., Canning, E. A., Tibbetts, Y., Priniski, S. J., \& Hyde, J. S. (2016). Closing achievement gaps with a utility-value intervention: Disentangling race and social class. Journal of Personality and Social Psychology, 111(5), 745-765.

Harackiewicz, J. M., Smith, J. L., \& Priniski, S. J. (2016). Interest matters: The importance of promoting interest in education. Policy Insights from the Behavioral and Brain Sciences, 3(2), 220-227.

Harding, S. (2016). Whose science? Whose knowledge? Thinking from women's lives. Ithaca, NY: Cornell University Press.

Harding, S. G. (1994). Is science multicultural? Challenges, resources, opportunities, uncertainties. Configurations, 2(2), 301-330

Higgins, E. T. (1996). Knowledge activation: Accessibility, applicability, and salience. In Higgins, E. T., \& Kruglanski, A. W. (Eds.), Social psychology: Handbook of basic principles (pp. 133-168). New York: Guilford.

Higgins, E. T., King, G. A., \& Mavin, G. H. (1982). Individual construct accessibility and subjective impressions and recall. Journal of Personality and Social Psychology, 43, 35-47.

Hulleman, C. S., Godes, O., Hendricks, B., \& Harackiewicz, J. M. (2010). Enhancing interest and performance with a utility value intervention. Journal of Educational Psychology, 102(4), 880-895.

Hulleman, C. S., \& Harackiewicz, J. M. (2009). Promoting interest and performance in high school science classes. Science, 326(5958), 1410 1412

Jackson, M. C., Galvez, G., Landa, I., Buonora, P., \& Thoman, D. B. (2016) Science that matters: The importance of a cultural connection in underrepresented students' science pursuit. CBE-Life Sciences Education, 15(3), ar42. doi: 10.1187/cbe.16-01-0067

Klotz, L., Potvin, G., Godwin, A., Cribbs, J., Hazari, Z., \& Barclay, N. (2014). Sustainability as a route to broadening participation in engineering. Journal of Engineering Education, 103(1), 137-153.

Knight, B. A. (2015). Teachers' use of textbooks in the digital age. Cogent Education, 2(1), 1015812. 
LaMeres, B. J., Burns, M. S., Thoman, D. B., \& Smith, J. L. (2019). The role of prosocial goal congruity on student motivation in electrical engineering. IEEE Transactions on Education, 99, 1-8.

Linnenbrink-Garcia, L., Durik, A. M., Conley, A. M., Barron, K. E., Tauer, J. M., Karabenick, S. A., \& Harackiewicz, J. M. (2010). Measuring situational interest in academic domains. Educational and Psychological Measurement, 70(4), 647-671.

Losier, G. F., \& Vallerand, R. J. (1994). The temporal relationship between perceived competence and self-determined motivation. Journal of Social Psychology, 134(6), 793-801.

McBride, M. (1994). The theme of individualism in mathematics education An examination of mathematics textbooks. For the Learning of Mathematics, 14(3), 36-42.

Morgan, C., Isaac, J. D., \& Sansone, C. (2001). The role of interest in understanding the career choices of female and male college students. Sex Roles, 44, 295-320. doi: 10.1023/A:1010929600004

Moulton-Tetlock, E. E., Ahn, J. N., Haines, E. L., \& Mason, M. F. (2018) Women's work: Remembering communal goals. Motivation Science, 5(2), 157-178.

National Science Board. (2020). Science and engineering indicators 2020 The state of U.S. science and engineering (NSB-2020-1). Alexandria, VA Retrieved May 26, 2020, from https://ncses.nsf.gov/pubs/nsb20201

National Science Foundation. (2019). Women, minorities, and persons with disabilities in science and engineering: 2019 (Special report NSF 19-304). Arlington, VA. Retrieved May 26, 2020, from https://ncses.nsf.gov/pubs/ nsf19304/

National Science Foundation Act of 1950. (1950). 42 U.S.C. J1861, et sea. Retrieved May 26, 2020, from https://www.nsf.gov/about/history/ legislation.pdf

Nguyen, B. M., Nguyen, M. H., Teranishi, R. T., \& Hune, S. (2015). The hidden academic opportunity gaps among Asian Americans and Pacific Islanders: What disaggregated data reveals in Washington State. Princeton, NJ: Educational Testing Service.

Pöhlmann, K. (2001). Agency- and communion-orientation in life goals: Impacts on goal pursuit strategies and psychological well-being. In Schmuck, P., \& Sheldon, K. M. (Eds.), Life goals and well-being: Towards a positive psychology of human striving (pp. 68-84). Seattle, WA: Hogrefe and Huber.

President's Council of Advisors on Science and Technology. (2012) Engage to excel: Producing one million additional college graduates with degrees in science, technology, engineering, and mathematics. Washington, DC: U.S. Government Office of Science and Technology.

Reece, J. B., Urry, L. A., Cain, M. L., Wasserman, S. A., Minorsky, P. V., \& Jackson, R. B. (2014). Campbell biology (10th ed.). San Francisco, CA: Pearson.

Remillard, J. T. (2005). Examining key concepts in research on teachers' use of mathematics curricula. Review of Educational Research, 75(2), 211-246.

Renninger, K. A., Nieswandt, M., \& Hidi, S. (2015). Interest in mathematics and science learning. Washington, DC: American Education Research Association.

Sansone, C. (1989). Competence feedback, task feedback, and intrinsic interest: An examination of process and context. Journal of Experimental Social Psychology, 25(4), 343-361.

Sansone, C. (2009). What's interest got to do with it?: Potential trade-offs in the self-regulation of motivation. In Forgas, J. P., Baumeister, R. F., \& Tice, D. M. (Eds.), Psychology of self-regulation: Cognitive, affective, and motivational processes (pp. 35-51). New York: Psychology Press.

Sansone, C., Smith, J. L., Thoman, D. B., \& MacNamara, A. (2012). Regulating interest when learning online: Potential motivation and performance trade-offs. The Internet and Higher Education, 15(3), 141-149.
Seymour, E., \& Hewitt, N. M. (1997). Talking about leaving: Why undergraduates leave the sciences. Boulder, CO: Westview.

Smith, J. L., Cech, E., Metz, A., Huntoon, M., \& Moyer, C. (2014). Giving back or giving up: Native American student experiences in science and engineering. Cultural Diversity and Ethnic Minority Psychology, 20(3), 413429.

Steinberg, M., \& Diekman, A. B. (2017). Elevating positivity toward STEM pathways through communal experience: The key role of beliefs that STEM affords other冈oriented goals. Analyses of Social Issues and Public Policy, 17(1), 235-261.

Steinberg, M., \& Diekman, A. B. (2018). Considering "why" to engage in STEM activities elevates communal content of STEM affordances. Journal of Experimental Social Psychology, 75, 107-114.

Stray, C. (1994). Paradigms regained: Towards a historical sociology of the textbook. Journal of Curriculum Studies, 26(1), 1-29.

Thoman, D. B., Brown, E. R., Mason, A. Z., Harmsen, A. G., \& Smith, J. L. (2015). The role of altruistic values in motivating underrepresented $\mathrm{mi}$ nority students for biomedicine. BioScience, 65(2), 183-188.

Thoman, D. B., Lee, G. A., Zambrano, J., Geerling, D. M., Smith, J. L., \& Sansone, C. (2019). Social influences of interest: Conceptualizing group differences in education through a self-regulation of motivation model. Group Processes \& Intergroup Relations, 22(3), $330-355$.

Thoman, D. B., Muragishi, G. A., \& Smith, J. L. (2017). Research microcultures as socialization contexts for underrepresented science students. Psychological Science, 28(6), 760-773.

Thoman, D. B., \& Sansone, C. (2016). Gender bias triggers diverging science interests between women and men: The role of activity interest appraisals. Motivation and Emotion, 40(3), 464-477.

Thoman, D. B., Smith, J. L., \& Silvia, P. J. (2011). The resource replenishment function of interest. Social Psychological and Personality Science, 2(6), 592-599.

Tibbetts, Y., Harackiewicz, J. M., Priniski, S. J., \& Canning, E. A. (2016). Broadening participation in the life sciences with social-psychological interventions. CBE-Life Sciences Education, 15(3), es4. doi: 10.1187/cbe.1601-0001

Titus, J. J. (1993). Gender messages in education foundations textbooks. Journal of Teacher Education, 44(1), 38-44.

Tro, N. (2010). Chemistry: A molecular approach (2nd ed.). New York: Prentice Hall.

Tyler, K. M., Boykin, A. W., Miller, O., \& Hurley, E. (2006). Cultural values in the home and school experiences of low-income African-American students. Social Psychology of Education, 9(4), 363-380.

Valla, J. M., \& Ceci, S. J. (2014). Breadth-based models of women's underrepresentation in STEM fields: An integrative commentary on Schmidt (2011) and Nye et al. (2012). Perspectives on Psychological Science, 9(2), 219224.

Weber, R., \& Crocker, J. (1983). Cognitive processes in the revision of stereotypic beliefs. Journal of Personality and Social Psychology, 45(5), $961-$ 977.

Weisgram, E. S., \& Bigler, R. S. (2006). Girls and science careers: The role of altruistic values and attitudes about scientific tasks. Journal of Applied Developmental Psychology, 27(4), 326-348.

Wigfield, A., \& Eccles, J. S. (2000). Expectancy-value theory of achievement motivation. Contemporary Educational Psychology, 25(1), 68-81.

Yeager, D. S., Henderson, M. D., Paunesku, D., Walton, G. M., D'Mello, S., Spitzer, B. J., \& Duckworth, A. L. (2014). Boring but important: A self-transcendent purpose for learning fosters academic self-regulation. Journal of Personality and Social Psychology, 107(4), 559 